Relations industrielles

Industrial Relations

\title{
La sécurité industrielle
}

Volume 1, numéro 7, mars 1946

URI : https://id.erudit.org/iderudit/1023939ar

DOI : https://doi.org/10.7202/1023939ar

Aller au sommaire du numéro

Éditeur(s)

Département des relations industrielles de l’Université Laval

\section{ISSN}

0034-379X (imprimé)

1703-8138 (numérique)

Découvrir la revue

Citer cet article

(1946). La sécurité industrielle. Relations industrielles / Industrial Relations,

1(7), 3-3. https://doi.org/10.7202/1023939ar

Tous droits réservés @ Département des relations industrielles de l’Université Laval, 1946
Ce document est protégé par la loi sur le droit d'auteur. L’utilisation des services d'Érudit (y compris la reproduction) est assujettie à sa politique d'utilisation que vous pouvez consulter en ligne.

https://apropos.erudit.org/fr/usagers/politique-dutilisation/ 


\section{LA SÉCURITÉ INDUSTRIELLE}

Beveridge, dans son bilan des revendications de la nation britannique, préconisait un plan qui avait pour but d'assurer la sécurité de l'individu : la compensation en cas de chômage ; l'aide aux malades.; le soutien des vieillards ; et enfin, la compensation au décès. C'est là une autre preuve que l'humanité désire au moins des palliatifs aux épreuves séculaires auxquelles les hommes ne peuvent se soustraire. En effet, malgré les efforts des économistes, il y a toujours eu des crises de chômage ; la maladie est inévitable ; la vieillesse nous attend tous ...

Il en est autrement de l'accident de travail : dans ce domaine, la compensation cède de plus en plus la place à la prévention. En matière de santé, on mentionne courageusement la médecine préventive comme une réalisation possible et désirable; la sécurité industrielle, pour sa part, est maintenant la résultante de l'application précise de principes scientifiques qui deviennent de plus en plus acceptés partout.

Cet exposé y gagnera en clarté s'il établit clairement notre bilan dans le domaine de la sécurité industrielle ; il sera alors plus facile de tirer des conclusions et de songer aux moyens pratiques d'améliorer les méthodes de prévention, de mieux grouper les bonnes volontés et d'obtenir, en fait, que l'usine devienne un endroit ou l'ouvrier gagne sa vie en toute sécurité.

\section{LES REALISATIONS EN MATILHE DE StGURITt} DANS LE QUEBEC

La première législation de prévention d'accidents adoptée en Amérique du Nord, date de 1867 : la Législature du Massachusetts, en l'année même de la naissance de la Confédération canadienne, constituait un Service d'inspection du Travail. Dix ans plus tard, les employeurs de cet Etat étaient assujettis à l'obligation légale de poser des gardes adéquates sur les machines dangereuses. Le seul autre Etat américain avant le Québec à légiférer indirectement dans ce domaine fut l'Alabama qui, avec le Massachusetts, adoptait, en 1885, une législation imposant à l'employeur la responsabilité en cas d'accident de travail : nous y retrouvons les principes de nos lois actuelles de compensation d'accidents.

Le Québec, se conformant comme l'Ontario aux recommandations d'une commission parlementaire fédérale, adoptait en 1885 l'Acte des Manufactures qui est devenu après plusieurs refontes notre Loi des établissements industriels et commercioux ; c'est la loi organique de sécurité et de prévention des accidents à l'usine. Son champ d'application est très vaste et le personnel d'inspection, nombreux et de plus en plus expérimenté, peut suffire à la mission qui lui a été confiée. On peut donc conclure que la province de Québec, dans le domaine législatif de la prévention des accidents, n'a pas été retardataire.

Le patronat et la classe ouvrière ont cependant vite réalisé qu'ils avaient aussi des responsabilités : les em- ployeurs, en raison d'un désir de diminuer des accidents provenant du fonctionnement de leur industrie et aussi pour éliminer une source de perte d'argent et d'ênergie; les ouvriers, afin de cesser de vivre au travail dans la crainte de l'accident et de ses conséquences désastreuses. La première intervention devait se manifester par la formation de sociétés patronales de prévention d'accidents; plus tard, elle prit la forme d'un effort conjoint des employeurs et des employés pour la prévention des accidents ; dans le Québec, on suivit l'exemple tracé aux Etats-Unis. Tout comme en 1915, un groupe d'enthousiastes jetait les bases du National Safety Council américain à la suite de l'adoption d'une législation portant sur la réparation des accidents du travail, de même, dans le Québec, la mise en vigueur de notre Loi des accidents du Travail, il y a seize ans, a précédé de quelque temps à peine la constitution d'une Association patronale de prévention des accidents du Travail. Ce groupement, aidé financièrement par la Commission des accidents du Travail, est de plus en plus actif. Il a de belles réalisations à son crédit et collabore intimement avec le Service gouvernemental d'inspection des établissements industriels et commerciaux. Son domaine comprend surlout l'éducation et la propagande.

Par ailleurs, nombreuses sont les usines où fonctionnent des comités mixtes de prévention d'accidents. Les ouvriers participent aux campagnes d'éducation, contribuent à déceler les risques et procèdent aux recommandations appropriées ; et l'expérience a prouvé que ces efforts sont couronnés de succès.

Tout comme dans un plan général des relations industrielles, nous retrouvons ici la collaboration tripartite :

$1^{\circ}$ celle de l'employeur qui, en plus de ses sentiments humanitaires, en arrive à son but légitime de réduire le coût de sa production au strict minimum en évitant des contributions excessives et inutiles au fonds commun de réparation d'accidents;

$\mathscr{2}^{\circ}$ celle de l'employé, soucieux de sécurité, très au courant soit directement soit indirectement des conséquences del'accident de travail et pour lui-même et pour ses dépendants ;

$3^{\circ}$ celle de l'Etat qui a, pour le bien commun, la mission, en élaborant et en appliquant des minima de sécurité, de suppléer à la carence de certains employeurs et de forcer les récalcitrants à suivre un mouvement essentiellement social et nécessaire.

Tout comme dans le domaine des relations industrielles, le deuxième conflit mondial nous a donné une profonde leçon en matière de sécurité industrielle. La nécessité en Amérique du Nord d'un effort total de guerre, exigeant une production sans cesse accrue et requérant l'intervention des gouvernements pour la prévention des arrêts de travail, a aussi intensifié le désir d'éliminer l'arrêt individuel de travail provenant de l'accident. Cette leçon va continuer de porter ses fruits et nous pourrons apprécier immédiatement ses conséquences. 